\title{
Leptin-induced lipolysis opposes the tonic inhibition of endogenous adenosine in white adipocytes
}

\author{
GEMA FRÜHBECK,*,§,1 JAVIER GÓMEZ-AMBROSI,* AND JAVIER SALVADOR ${ }^{\S}$ \\ *Metabolic Research Laboratory, University of Navarra, and ${ }^{\S}$ Department of Endocrinology, Clínica \\ Universitaria de Navarra, 31008-Pamplona, Spain
}

ABSTRACT The aim of the present study was to gain insight into the signaling pathway used by leptin to stimulate lipolysis. The lipolytic rate of white adipocytes from sex- and age-matched lean $(+/+)$ and $f a / f a$ rats was determined in the absence or presence of leptin together with a number of agents acting at different levels of the signaling cascade. Leptin did not modify FSK-, dbcAMP-, and IBMX-stimulated lipolysis. Lipolysis can also be maximally stimulated by lowering media adenosine levels with adenosine deaminase (ADA), i.e., in the ligand-free state. Although ADA produced near maximal lipolysis in adipocytes of lean animals, only half of the maximal lipolytic rate $(50.9 \pm 3.2 \%)$ was achieved in fat cells from $f a / f a$ rats $(P=0.0034)$. In adipocytes from lean animals preincubated with ADA, leptin caused a concentration-related stimulation of lipolysis $(P=0.0001)$. However, leptin had no effect on the lipolytic activity of adipocytes in the ligand-free state from $f a / f a$ rats. The adenosine $\mathrm{A}_{1}$ receptor agonist CPA effectively inhibited basal lipolysis in both lean and obese adipocytes $(P=0.0001$ and $P=0.0090$, respectively). Leptin had no effect on the lipolytic rate of adipocytes isolated from $f a / f a$ rats and preincubated with CPA. When adipocytes were incubated with the $A_{1}$ receptor antagonist DPCPX, a significant increase in glycerol release was observed in $f a / f a$ fat cells $(P=0.009)$, whereas cells isolated from lean rats showed no differences to ADA-stimulated lipolysis. After pretreatment with PTX, which inactivates receptor-mediated $G_{i}$ function, adipocytes of obese rats became as responsive to the stimulatory actions of ISO as cells from lean rats $(P=0.0090 \mathrm{vs.}$ ISO in $f a / f a$ rats; $P=0.2416$ vs. lean rats, respectively). PTX treatment of lean cells, however, did not alter their response to this lipolytic agent. It can be concluded that the lipolytic effect of leptin is located at the adenylate cyclase $/ G_{i}$ proteins level and that leptin-induced lipolysis opposes the tonic inhibition of endogenous adenosine in white adipocytes.-Frühbeck, G., Gómez-Ambrosi, J., Salvador, J. Leptin-induced lipolysis opposes the tonic inhibition of endogenous adenosine in white adipocytes. FASEB J. 15, 333-340 (2001)

Key Words: OB protein $\cdot$ catecholamines $\cdot$ G-proteins $\cdot$ obesity - lipid metabolism

UNRAVELING THE DIVERSE hormonal and neuroendocrine systems that regulate energy balance and body fat has been a long-standing challenge in biology, with obesity an increasingly important public health focus. A major development in energy balance regulation came with the discovery in 1994 of leptin, the protein product of the $o b$ gene (1). The initial concept was that leptin informs the brain about the abundance of body fat, thereby allowing feeding behavior, metabolism, and endocrine physiology to be coupled to the nutritional state of the organism (2). The original view, however, has evolved considerably over recent years with the finding of the extreme functional pleiotropy of leptin and its involvement in such diverse physiological functions as reproduction (3), hematopoiesis (4), angiogenesis (5), immune responsiveness (6), and blood pressure control (7).

Adenoviral transfer of the leptin gene into rats has been shown to dramatically reduce tissue triglyceride stores compared with pair-fed controls, providing evidence for a role for leptin beyond its appetite-reducing properties $(8,9)$. Despite equivalent reductions in food intake and weight gain in hyperleptinemic rats by adenoviral transfer of the leptin gene and pair-fed animals, identifiable fat tissue was completely ablated only in the former group. Fat could not be identified in either subcutaneous, visceral, retroperitoneal, or epididymal fat depots of hyperleptinemic adenovirally transferred rats. In pair-fed animals, fat depots were preserved in all sites, although below normal control levels (8). The lipopenic action of hyperleptinemia on adipocytes has been reported not to be mediated by neurotransmitted signals from the central nervous system (10). The same group has demonstrated a novel form of lipolysis by which the leptin-induced glycerol release is not accompanied by a rise in plasma free fatty acids (11). Previous studies have also shown an autocrine-paracrine lipolytic effect of leptin on white adipose tissue both in vitro and in vivo (12-14). However, the mechanisms of leptin-induced lipolysis still remain to be completely elucidated.

Lipolysis is controlled by intracellular cAMP, whose concentrations in fat cells are influenced by activation of receptors interacting with adenylate cyclase. Acting through the $A_{1}$ receptor on the adipocyte plasma membrane coupled to the inhibitory guanosine $5^{\prime}$ -

\footnotetext{
${ }^{1}$ Correspondence: Department of Endocrinology, Clínica Universitaria de Navarra, 31008-Pamplona, Spain. E-mail: gfruhbeck@unav.es
} 
triphosphate (GTP) binding proteins $G_{i}$, adenosine is implicated in the regulation of adenylate cyclase and, therefore, in lipolysis control $(15,16)$. Endogenously released adenosine provides a tonic inhibition of lipolysis in isolated adipocytes. Addition of adenosine deaminase (ADA) to fat cell incubations results in the 'ligand-free' state described by Honnor et al. (15), i.e., when tonic inhibition by adenosine is removed in adipocytes from fasted animals and maximal rates of lipolysis can be achieved. Activation of the sympathetic nervous system also contributes to the control of adipose tissue metabolism. The modulatory effects of catecholamines on fat cell function involve various adrenoreceptor subtypes connected with different transducing systems (17). Fat mobilization is mediated mainly by $\beta$-adrenergic agonists and lipolysis stimulation.

The regulatory nature of lipolysis in fat cells permits the pharmacological dissection of the site of action of lipolytic agents. The aim of the present study, therefore, was to gain further insight into the signaling pathway used by leptin to stimulate lipolysis. Agents acting at the $\beta$-adrenoreceptor, adenylate cyclase, $A_{1}$ adenosine receptor, phosphodiesterase, and protein kinase A levels were assayed in vitro on fat cells from control rats in the presence or absence of leptin. The same combinations of lipolytic agents were further studied in adipocytes isolated from sex- and agematched obese Zucker $(f a / f a)$ rats to examine the effect of defective leptin receptors on the stimulation of lipolysis.

\section{MATERIALS AND METHODS}

\section{Animals}

Experiments were performed in 3-month-old male lean $(+/+)$ and obese Zucker $(f a / f a)$ rats (Harlan, Oxon, U.K.). All experimental procedures conformed to the National Institute of Health Guide for the Care and Use of Laboratory Animals.

\section{Adipocyte isolation and lipolysis measurements}

Isolation of adipocytes from lean and obese rats was performed following the method of Rodbell (18) as modified by Galitzky et al. (19) and as described earlier (13, 14). Briefly, minced abdominal fat depots were digested at $37^{\circ} \mathrm{C}$ for 90 min with collagenase $\mathrm{P}$ in Krebs-Ringer bicarbonate buffer containing albumin $(3.5 \mathrm{~g} / 100 \mathrm{ml})$ and glucose $(6 \mathrm{mM})$ at $\mathrm{pH} 7.4$ (KRBA). The ratio of digestion solution to adipose tissue mass was $5 \mathrm{ml} / \mathrm{g}$ and $0.75 \mathrm{ml}$ of $\mathrm{KRBA} / \mathrm{mg}$ of collagenase. The fat samples were incubated in $50 \mathrm{ml}$ polypropylene vials under continuous vigorous shaking (90 cycles/min). After the digestion period, cell suspension was filtered through nylon mesh and washed three times with KRBA to eliminate the stromavascular fraction and collagenase. The disaggregated fat cells were brought to a suitable dilution in KRBA buffer. Adipocytes were incubated in polyethylene tubes with continuous gentle shaking (30 cycles/min) in a water bath at $37^{\circ} \mathrm{C}$. Lipolysis was determined in the absence or presence of leptin $(0.63,6.25$, and $62.5 \mathrm{nM})$ together with a number of agents acting at different levels of the signaling cascade: 1 ) at the $\beta$-adrenoreceptor [isoproterenol (ISO, 1 $\mu \mathrm{M})$ ]; 2) at the adenylate cyclase [forskolin (FSK $10 \mu \mathrm{M})$ and adenosine deaminase (ADA $10 \mu \mathrm{g} / \mathrm{ml}$ ) ]; 3) at the $\mathrm{A}_{1}$ adenosine receptor $\left[\mathrm{N}^{6}\right.$-cyclopentyladenosine $(\mathrm{CPA}, 10 \mu \mathrm{M})$ and 8-cyclopentyl-1,3-dipropylxanthine (DPCPX, $1 \mu \mathrm{M})$ ]; 4) at the phosphodiesterase [isobutylmethylxanthine (IBMX, 0.1 $\mathrm{mM})$; 5) at the protein kinase A [dibutyryl-cyclic AMP (dbcAMP, $1 \mathrm{mM})]$. After $90 \mathrm{~min}$, the incubation tubes were placed in an ice bath and $200 \mu \mathrm{l}$ of the infranatant was removed for enzymatic determination of glycerol released into the incubation medium, which was taken as the index of lipolytic rate (20). Total lipid content was evaluated gravimetrically after extraction as described by Dole and Meinertz (21). The maximal lipolytic response was achieved in adipocytes isolated from both lean and obese rats by incubation with IBMX $0.1 \mathrm{mM}$. This IBMX-stimulated lipolysis value obtained in $(+/+)$ and $(f a / f a)$ fat cells was used as $100 \%$ of stimulation for the lean and obese groups, respectively.

\section{Treatment of isolated adipocytes with pertussis toxin}

Adipocytes were prepared as described above but were resuspended in KRBA containing $5 \%$ albumin and $200 \mathrm{nM}$ adenosine. Pertussis toxin (PTX) was added to a final concentration of $350 \mathrm{ng} / \mathrm{ml}$, and the cells were maintained with gentle stirring at $37^{\circ} \mathrm{C}$. At $30 \mathrm{~min}$ intervals, fat cells were resuspended in fresh buffer. Effectiveness of the PTX treatment was assessed by the loss of receptor-mediated CPA inhibition of FSK-stimulated activity. Adipocytes isolated from lean rats required $2 \mathrm{~h}$ for effective PTX treatment, whereas 90 min was sufficient to abolish receptor-mediated $G_{i}$ activity in fat cells obtained from $f a / f a$ animals. At the end of the incubation period, adipocytes were washed free of PTX and incubated under the experimental conditions described.

\section{Drugs}

Recombinant murine leptin was purchased from PeproTech EC Ltd. (London, U.K.). The OB protein showed more than 95\% purity as evidenced by sodium dodecyl sulfate-polyacrylamide gel electrophoresis and high-performance liquid chromatography analyses. Leptin was dissolved in phosphatebuffered saline at $\mathrm{pH}$ 7.4. Bovine serum albumin (fraction V), FSK, dbcAMP, IBMX, ISO bitartrate salt, and PTX were obtained from Sigma Chemical Co. (St. Louis, Mo.). CPA and DPCPX were purchased from ICN Biomedicals Ltd. (Oxfordshire, U.K.). Collagenase P (from Clostridium histolyticum, activity $1.52 \mathrm{U} / \mathrm{mg}$ ), ADA, glycerol-3-phosphate dehydrogenase, and glycerol kinase were obtained from Boehringer Mannheim GmbH (Mannheim, Germany). All drugs were made fresh on the day of the experiment.

\section{Data analyses}

Results are presented as means \pm SE of separate experiments performed in duplicate. Intergroup differences were computed by one-way analysis of variance (ANOVA), followed by Scheffe's $F$ test for post hoc pairwise comparisons. Dosedependency was tested by a factorial ANOVA using linear trend testing. Changes from baseline were studied by Student's two-tailed, paired $t$ test. Within the lean group the effect of the lipolytic agents in the different pharmacological settings was analyzed by Student's two-tailed, unpaired $t$ tests. The nonparametric Kruskal-Wallis test, followed by U MannWhitney's pairwise comparisons was applied due to the small number of animals used in the lipolytic experiments carried out on $f a / f a$ rats. Responses to the same pharmacological 
treatment in adipocytes obtained from lean and obese rats were compared by U Mann-Whitney's tests. Analyses were performed using the StatView 4.01 Non-FPU (Abacus Concepts, Inc. ${ }^{\odot} 1992-93$, Berkeley, Calif.) statistical package for Apple Macintosh computers. Differences were considered statistically significant at the $P<0.05$ level.

\section{RESULTS}

Effect of leptin on basal and maximally stimulated lipolysis

In adipocytes obtained from lean rats the three leptin concentrations tested $(0.63,6.25$, and $62.5 \mathrm{nM})$ produced a statistically significant increase in the basal lipolytic rate $(F=34.65 ; \quad P=0.0001 ;$ saline control: $0.571 \pm 0.015 \mu \mathrm{mol}$ glycerol $/ 100 \mathrm{mg}$ lipids; Fig. 1). The highest dose of leptin produced a $57.5 \pm 7.3 \%$ increase in glycerol release compared to the basal lipolytic rate $(P<0.001)$. The lowest dose of leptin produced a more modest increase in the glycerol released to the incubation medium $(21.5 \pm 0.8 \%)$, which was also significantly different from the saline control $(P<0.05)$. The effect of leptin on lipolysis was significantly dose dependent on linear trend testing $(P=0.0001)$.

To study the influence of leptin on different steps of the signal transduction pathway, the effect of the OB

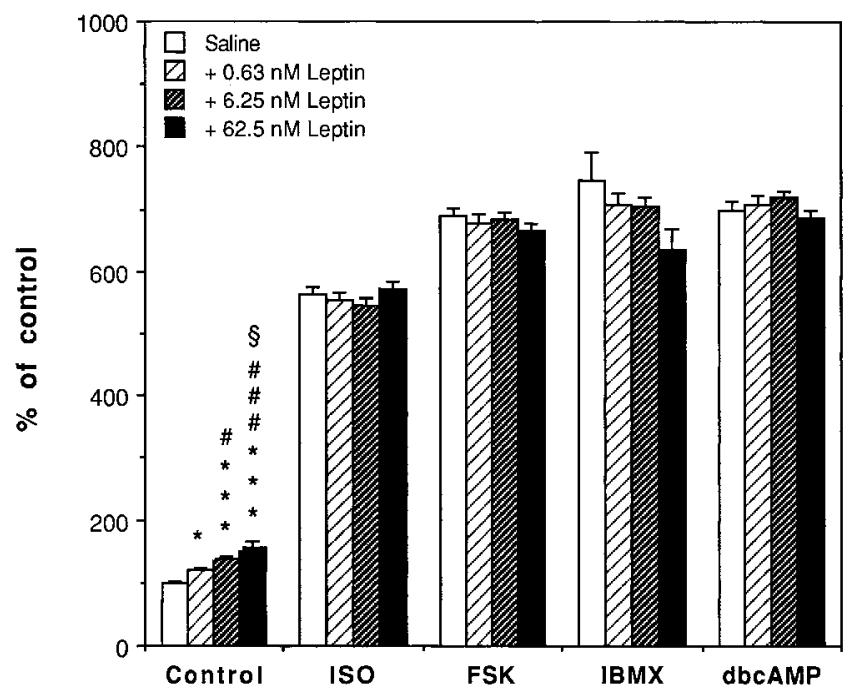

Figure 1. Effect of leptin on basal (control) and stimulated lipolysis in adipocytes of lean rats. The lipolytic rate was measured as the amount of glycerol released after $90 \mathrm{~min}$ of incubation with three doses of leptin and treatment with isoproterenol (ISO $1 \mu \mathrm{M}$ ), forskolin (FSK $10 \mu \mathrm{M}$ ), isobutylmethylxanthine (IBMX $0.1 \mathrm{mM}$ ), and dibutyryl-cyclic AMP (dbcAMP $1 \mathrm{mM})$. Data are normalized to basal lipolysis of fat cells from saline-treated animals (saline control: $0.571 \pm$ $0.015 \mu \mathrm{mol}$ glycerol $/ 100 \mathrm{mg}$ lipids $)$ and are means $\pm \operatorname{SE}(n=8$ per group; lipolytic experiments were performed in duplicate). Statistical comparisons were made by ANOVA, followed by Scheffe's post hoc pairwise comparisons; $* P<0.05$, $* * * P<0.001$ vs. saline; ${ }^{\#} P<0.05$, ${ }^{\# \# \#} P<0.001$ vs. $0.63 \mathrm{nM}$ leptin; ${ }^{\S} P<0.05$ vs. $6.25 \mathrm{nM}$ leptin.

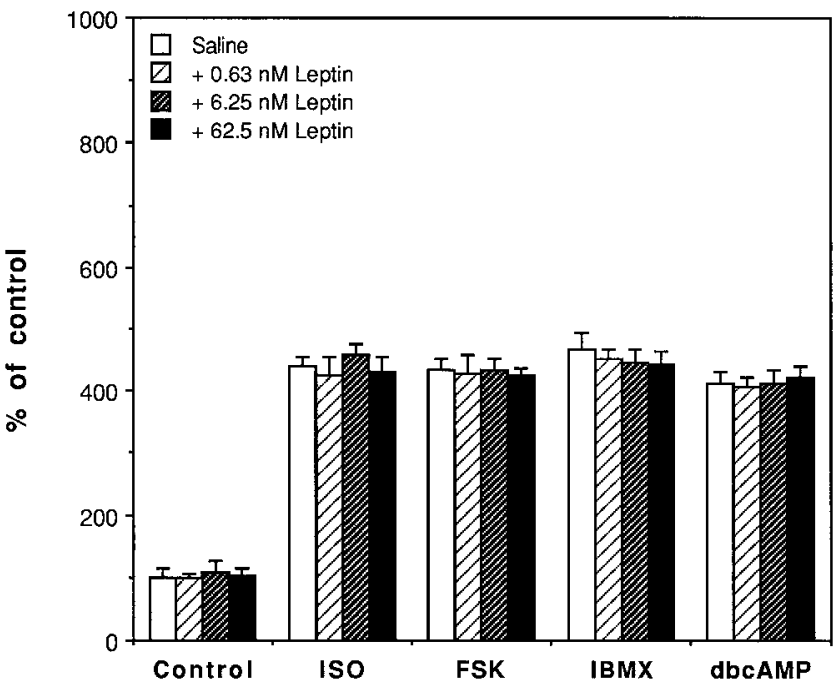

Figure 2. Effect of leptin on basal (control) and stimulated lipolysis in adipocytes of $f a / f a$ rats. The lipolytic rate was measured as the amount of glycerol released after $90 \mathrm{~min}$ of incubation with three doses of leptin and treatment with isoproterenol (ISO $1 \mu \mathrm{M}$ ), forskolin (FSK $10 \mu \mathrm{M}$ ), isobutylmethylxanthine (IBMX $0.1 \mathrm{mM}$ ), and dibutyryl-cyclic AMP (dbcAMP $1 \mathrm{mM})$. Data are normalized to basal lipolysis of fat cells from saline-treated obese animals (saline control: $0.443 \pm 0.062 \mu \mathrm{mol}$ glycerol $/ 100 \mathrm{mg}$ lipids) and are means \pm SE $(n=5$ per group; lipolytic experiments were performed in duplicate). Statistical comparisons were made by the KruskalWallis test.

protein on ISO-, FSK-, IBMX-, and dbcAMP-stimulated lipolysis was analyzed. None of the three leptin concentrations tested modified the maximal lipolytic stimulation elicited by ISO, FSK, and dbcAMP in fat cells of lean animals (Fig. 1). Although a marked decrease in the release of glycerol was observed in IBMX-treated adipocytes after exposure to leptin, it did not reach statistical significance $(P=0.09)$.

As expected, addition of leptin to the incubation medium did not alter the lipolytic rate of white adipocytes obtained from $f a / f a$ rats, the mutant rodents that lack functional leptin receptors. However, incubation of fat cells of obese Zucker animals with ISO, FSK, IBMX, and dbcAMP produced a marked lipolytic response $(P<0.001)$, thus showing that the adipocyte preparations from these rats are not defective to other known lipolytic agents (Fig. 2). In these adipocytes, addition of leptin had no effect on ISO-, FSK-, IBMX-, and dbcAMP-stimulated lipolysis either.

\section{Basal lipolysis in the absence of adenosine}

Lipolysis in isolated adipocytes can be maximally stimulated in the absence of added $\beta$-agonists by lowering media adenosine levels with ADA. Although ADA produced near maximal lipolysis in adipocytes of lean animals (Fig. 3), only half of the maximal lipolytic rate $(50.9 \pm 3.2 \%)$ was achieved in fat cells from $f a / f a$ rats $(P=0.0034)$. In adipocytes from lean animals preincubated with ADA, leptin caused a concentration-related 


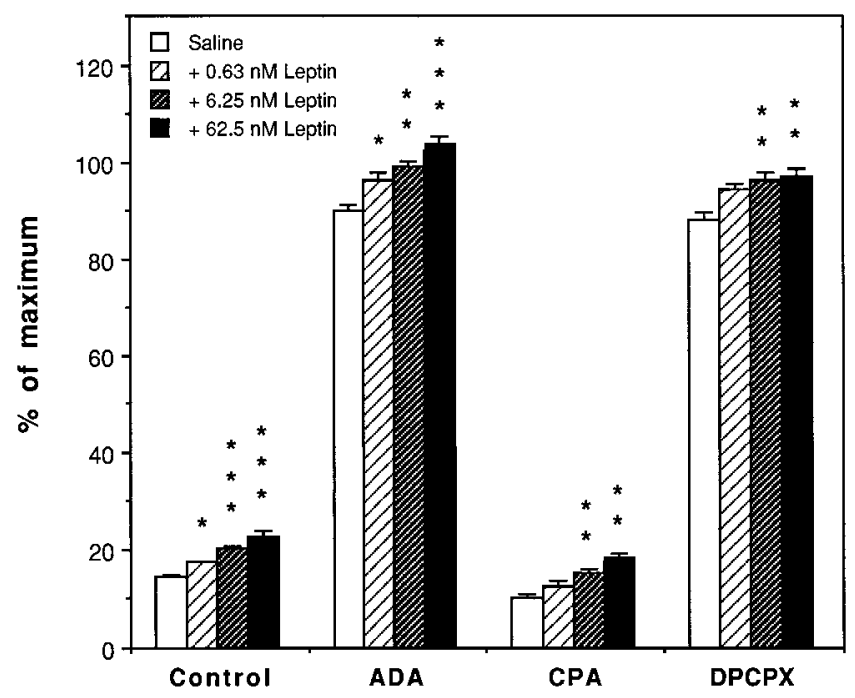

Figure 3. Effect of leptin on basal (control) and stimulated lipolysis in adipocytes of lean rats. The lipolytic rate was measured as the amount of glycerol released after $90 \mathrm{~min}$ of incubation with three doses of leptin and treatment with adenosine deaminase (ADA $10 \mu \mathrm{g} / \mathrm{ml}$ ), the $A_{1}$ adenosine receptor agonist $\mathrm{N}^{6}$-cyclopentyladenosine $(\mathrm{CPA} 10 \mu \mathrm{M})$, and the $\mathrm{A}_{1}$ adenosine receptor antagonist dibutyryl-cyclic AMP (dbcAMP $1 \mathrm{mM}$ ). Results are expressed as the percent of maximally stimulated lipolysis of fat cells from lean animals (maximum: $3.944 \pm 0.072 \mu \mathrm{mol}$ glycerol/100 mg lipids) and are means \pm SE ( $n=8$ per group; lipolytic experiments were performed in duplicate). Statistical comparisons were made by ANOVA, followed by Scheffe's post hoc pairwise comparisons; $* P<0.05, * * P<0.01, * * * P<0.001$ vs. saline.

stimulation of lipolysis $(P=0.0001)$. Addition of the three leptin concentrations $(0.63,6.25$, and $62.5 \mathrm{nM})$ in the ligand-free state $(44.0 \pm 10.3 \%, 64.4 \pm 7.5 \%$, and $94.6 \pm 13.4 \%$ of the saline control, respectively) compared to the basal control condition $(21.5 \pm 0.8 \%$, $39.8 \pm 3.1 \%$, and $57.5 \pm 7.3 \%$ of the saline control, respectively) produced a statistically significant increase in the stimulation of lipolysis $(P=0.048 ; P=0.009$, and $P=0.029$, respectively) of fat cells obtained from lean animals. On the contrary, leptin had no effect on the lipolytic activity of adipocytes in the ligand-free state from $f a / f a$ rats (Fig. 4).

\section{Effect of $A_{1}$ agonism on lipolysis}

The adenosine $A_{1}$ receptor agonist CPA effectively inhibited basal lipolysis in both lean and obese adipocytes $(P=0.0001$ and $P=0.0090$, respectively). Addition of the higher concentrations of leptin to fat cells from lean animals pretreated with CPA was followed by a statistically significant $(P<0.01)$ stimulation of lipolysis compared to the basal adenosine $\mathrm{A}_{1}$ receptor agonism state. The lowest dose of leptin tested produced a more modest increase in glycerol release that was not significantly different from the saline control. Addition of the three leptin concentrations to adipocytes under $A_{1}$ receptor agonism of lean rats $(12.5 \pm 1.3 \%, 15.2 \pm 0.7 \%$, and $18.2 \pm 0.9 \%$ of maximal lipolysis, respectively) compared to the control conditions
$(17.6 \pm 0.2 \%, 20.2 \pm 0.4 \%$, and $22.8 \pm 1.1 \%$ of maximal lipolysis, respectively) yielded consistently lower rates of lipolysis $(P<0.006)$. In the presence of CPA, adipocytes isolated from lean rats exhibited a statistically lower lipolytic activity than fat cells obtained from $f a / f a$ animals $(10.2 \pm 0.7 \%$ vs. $13.4 \pm 0.5 \%$ of maximal lipolysis, respectively; $P=0.0084$ ). Leptin had no effect on the lipolytic rate of adipocytes isolated from $f a / f a$ rats and preincubated with CPA.

\section{Effect of $A_{1}$ antagonism on lipolysis}

To further characterize the influence of the $\mathrm{A}_{1}$ adenosine receptor in lipolysis, the effect of the $A_{1}$ receptor antagonist DPCPX was studied. When adipocytes were incubated with DPCPX, a statistically significant increase in glycerol release was observed in $f a / f a$ fat cells $(P=0.009)$ whereas cells isolated from lean rats showed no differences to ADA-stimulated lipolysis $(P=0.3811)$. Only addition of the higher concentrations of leptin to the incubation medium of fat cells under $A_{1}$ receptor antagonism from lean rats was followed by a statistically significant $(P<0.01)$ stimulation of lipolysis. As before, leptin had no effect on the lipolytic activity of adipocytes isolated from $f a / f a$ rats and pretreated with DPCPX (Fig. 4).

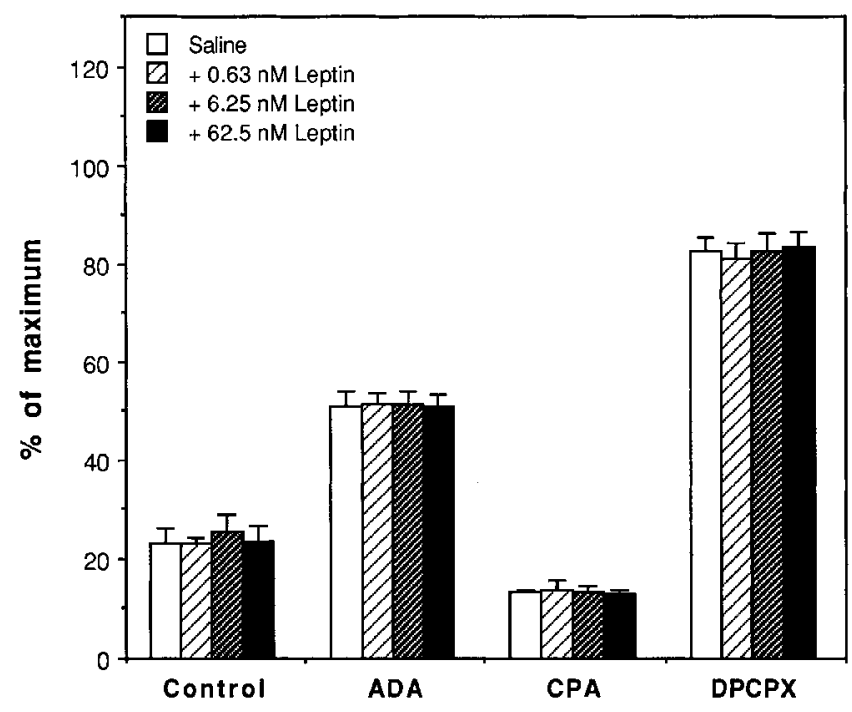

Figure 4. Effect of leptin on basal (control) and stimulated lipolysis in adipocytes of $f a / f a$ rats. The lipolytic rate was measured as the amount of glycerol released after $90 \mathrm{~min}$ of incubation with three doses of leptin and treatment with adenosine deaminase (ADA $10 \mu \mathrm{g} / \mathrm{ml}$ ), the $A_{1}$ adenosine receptor agonist $\mathrm{N}^{6}$-cyclopentyladenosine (CPA $\left.10 \mu \mathrm{M}\right)$, and the $\mathrm{A}_{1}$ adenosine receptor antagonist dibutyryl-cyclic AMP (dbcAMP $1 \mathrm{mM}$ ). Results are expressed as the percent of maximally stimulated lipolysis of fat cells from obese animals (maximum: 1.916 $\pm 0.090 \mu \mathrm{mol}$ glycerol $/ 100 \mathrm{mg}$ lipids) and are means $\pm \mathrm{SE}(n=5$ per group; lipolytic experiments were performed in duplicate). Statistical comparisons were made by the Kruskal-Wallis test. 


\section{Pertussis toxin treatment of adipocytes}

The possibility that receptor $\mathrm{G}_{\mathrm{i}}$-mediated inhibition of adenylate cyclase might cause the reduced sensitivity to lipolytic hormones observed in $f a / f a$ fat cells was tested by treating the cells with PTX. After pretreatment with the toxin, adipocytes of obese rats became as responsive to the stimulatory actions of ISO as cells from lean rats $(P=0.0090$ vs. ISO in $f a / f a$ rats; $P=0.2416$ vs. lean rats, respectively). PTX treatment of lean cells, however, did not alter their response to this lipolytic agent $(P=0.5059)$ (Fig. 5).

Pertussis toxin effectively inactivated receptor-mediated $\mathrm{G}_{\mathrm{i}}$ function as demonstrated by the inability of CPA to inhibit FSK-stimulated lipolysis in the treated adipocytes. Addition of leptin to the incubation medium of lean adipocytes under these experimental conditions resulted in a dose-dependent increase in the lipolytic rate (Fig. 6). Whereas leptin did not modify FSK-stimulated lipolysis under physiological circumstances, after PTX treatment leptin produced a statistically significant $(P=0.0001)$ increase in glycerol release of lean adipocytes. As before, incubating fat cells obtained from $f a / f a$ rats with leptin, even under the pharmacological setting of inactivating the inhibitory arm of the pathway by PTX pretreatment, had no significant effect on lipolysis compared to the saline control (Fig. 6).

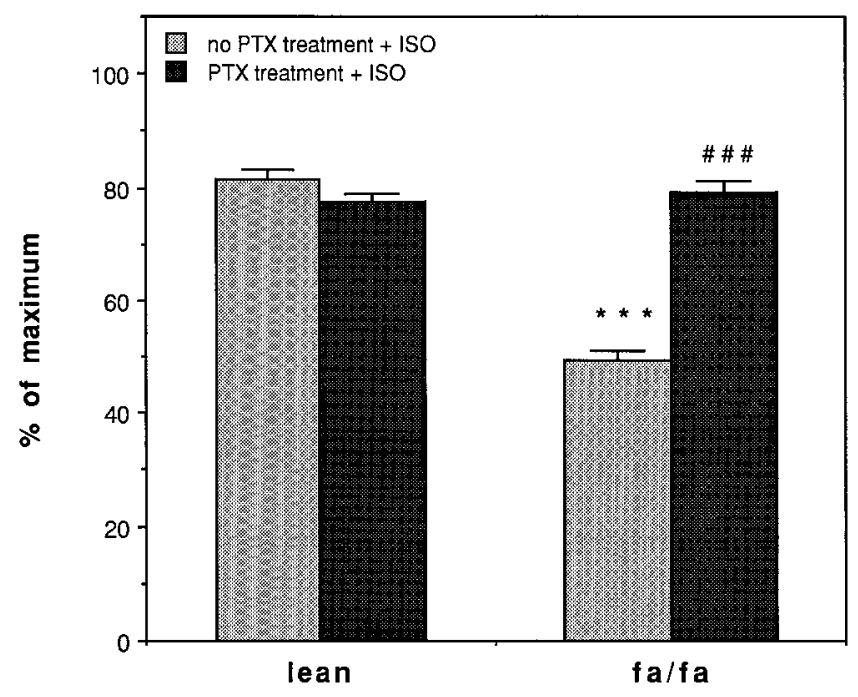

Figure 5. Comparison of the effect of pertussis toxin (PTX) treatment on isoproterenol (ISO $1 \mu \mathrm{M}$ )-stimulated lipolysis of adipocytes isolated from lean and obese rats. As in Figs. 3 and 4, data are normalized to maximally stimulated lipolysis of fat cells from lean and obese groups, respectively, and are means $\pm \mathrm{SE}$ ( $n=8$ per group in lean rats; $n=5$ per group in $\mathrm{fa} / \mathrm{fa}$ rats; lipolytic experiments were performed in duplicate). Statistical comparisons were made by U Mann-Whitney's test; *** $P<0.001$ vs. the same drug group of lean rats; ${ }^{\# \# \#} P<0.001$ vs. no PTX treatment within the obese group.

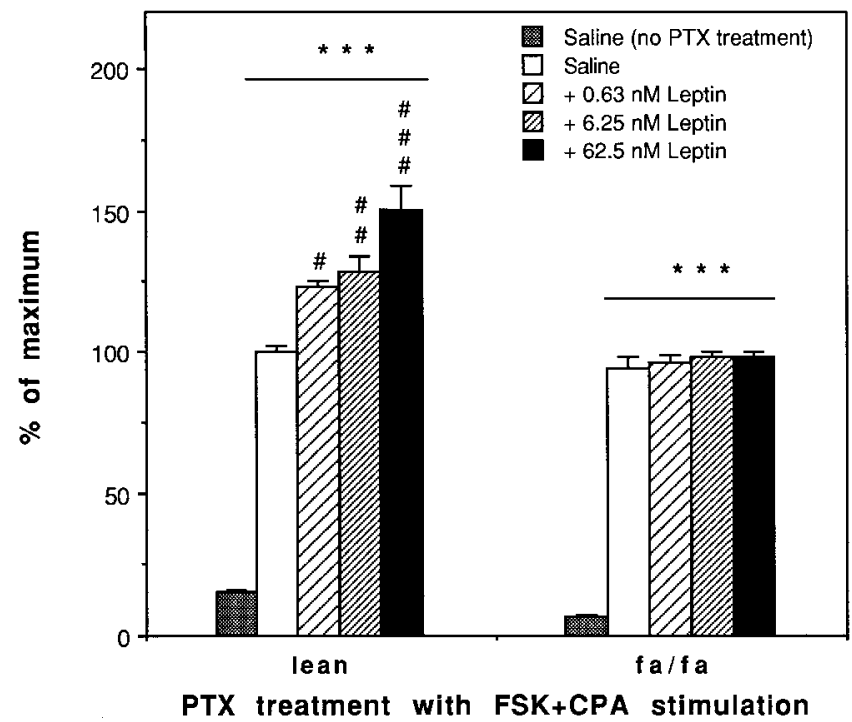

Figure 6. Comparative effects of pertussis toxin (PTX) treatment on the addition of leptin to forskolin-stimulated lipolysis of adipocytes obtained from lean and $f a / f a$ rats. Forskolinstimulated lipolysis was taken as $100 \%$. Effectiveness of PTX treatment was assessed by the loss of receptor-mediated $\mathrm{N}^{6}$-cyclopentyladenosine (CPA $\left.10 \mu \mathrm{M}\right)$ inhibition of forskolin-stimulated activity. Statistical comparisons were made by ANOVA, followed by Scheffe's post hoc pairwise comparisons in the lean rats. In obese Zucker rats, statistical comparisons were made by the Kruskal-Wallis test, followed by U MannWhitney's tests for pairwise comparisons; $* * * P<0.001$ vs. saline not pretreated with PTX; ${ }^{\#} P<0.05,{ }^{\# \#} P<0.01$,

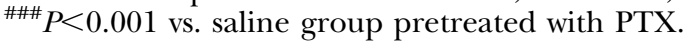

\section{DISGUSSION}

Although leptin-induced lipolysis has been described (11-14), the underlying mechanisms still remain to be elucidated. The lipolytic effect clearly needs functionally competent leptin receptors since it could not be replicated in adipocytes of obese Zucker rats, which are known to harbor a partially inactivating mutation in the leptin receptor gene. In the present study, the lack of effect of leptin on ISO-induced lipolysis in the in vitro assays suggests that leptin does not interfere with catecholamine-mediated lipolysis through interaction with the $\beta$-adrenergic receptors. Furthermore, the lack of effect of leptin on dbcAMP-mediated lipolysis suggests that the hormone does not interfere at the protein kinase A level either. Although a marked decrease in the release of glycerol was observed in IBMX-treated adipocytes after exposure to leptin, it did not reach statistical significance. However, the possibility that leptin may interfere at the phosphodiesterase level should not be ruled out completely. This assertion is also based on previous studies reporting a short-term inhibition of insulin secretion by leptin through a phosphodiesterase-dependent effect on cAMP concentrations $(22,23)$.

The dual regulatory nature of the adenylate cyclase system in the adipocyte allows us to pharmacologically dissect the site of action of lipolytic agents. The $A_{1}$ adenosine receptor is a typical transmembrane, $G_{i}$ 
protein-linked receptor widely distributed in adipose tissue and best known for its capacity to inhibit adenylyl cyclase (24). To gain insight into the likely mechanisms implicated, lipolysis was stimulated by addition of ADA, which degrades the adenosine that is endogenously released by isolated adipocyte preparations. Although ADA produced nearly maximal lipolysis in lean fat cells, in adipocytes obtained from $f a / f a$ rats only half of the maximal rate of lipolysis was achieved. Addition of the $\mathrm{A}_{1}$ adenosine receptor agonist CPA effectively inhibited basal lipolysis in both lean and obese adipocytes. To further validate the underlying assumption that leptin is involved in the modulation of lipolysis at the adenosinergic level, the effect on glycerol release of the adenosine $A_{1}$ receptor antagonist DPCPX was studied. When the influence of $A_{1}$ receptors on lipolysis is blocked by DPCPX, the stimulatory effect on the lipolytic rate clearly outweighs the absent tonic influences, leading to near maximal lipolysis stimulation. In our study a wide range of leptin concentrations encompassing the physiological values were tested. It is noteworthy that leptin at concentrations as low as $0.1 \mathrm{nM}$ has been shown to stimulate basal lipolysis in white fat pads $e x$ vivo in a time- and dose-dependent manner (12). The fact that under pharmacologically induced $A_{1}$ adenosine receptor agonism and antagonism, only the highest doses of leptin effectively increased the lipolytic rate of lean fat cells points to the possibility that the mediation of lipolysis stimulation by leptin may only be partial and not complete. A similar response in physiological function can therefore be considered.

Thus, removal of adenosine by treatment of adipocytes with ADA did not stimulate lipolysis in the obese animal to the same extent it did in control lean rats. However, low lipolytic rates observed in fat cells from obese rats could be stimulated to rates observed in lean fat cells either by treatment with $\mathrm{A}_{1}$ adenosine antagonist or by prior treatment with PTX, which uncouples $\mathrm{G}_{\mathrm{i}}$ from its receptor. If the inherent tonic activity of $\mathrm{G}_{\mathrm{i}}$ is pharmacologically eliminated an increase in lipolysis can be observed, i.e., inactivating the inhibitory arm of the signaling pathway results in a predominance of lipolysis stimulation over inhibition. Under these experimental conditions, direct stimulation of adenylyl cyclase by FSK, which directly activates the catalytic component of adenylyl cyclase without receptor or $\mathrm{G}_{\mathrm{s}}$ involvement, produced equivalent responses in lean and obese adipocytes.

The involvement of leptin in adenylate cyclase activity in the transmembrane adenosinergic signaling system of adipocytes is feasible from both a genetic and biochemical/functional point of view. The ADA gene is among the candidate genes with evidence of linkage to body fat (24-27). Furthermore, suppression of $G_{i \alpha 2}$ expression in adipocytes of transgenic mice by means of inducible antisense RNA reduced fat deposition (28), suggesting the relevance of $\mathrm{G}_{\mathrm{i}}$ proteins in mediating the inhibitory regulation of the adenylyl cyclase in vivo.

Our findings agree with previous observations reporting abnormalities in the adenylyl cyclase transmem- brane signaling system from genetically obese rodents and humans (24, 29-38). Researchers have observed that adenylate cyclase is less sensitive to stimulation by $\beta$-adrenergic hormones and more sensitive to inhibition by $\mathrm{A}_{1}$ adenosine agonism in adipocyte membranes isolated from leptin-deficient $o b / o b$ mice relative to membranes isolated from lean littermates $(24,29,30)$. Neither the amount of $\mathrm{G}_{\mathrm{i}}$ nor receptor density can be used as an explanation for the abnormally active inhibitory arm of the adenylyl cyclase system. Comparative estimates of $G_{i}$ and $G_{s}$ in plasma membranes from adipocytes did not support the notion that the abnormal signal behavior was due to an excess of $\mathrm{G}_{\mathrm{i}}(24)$. On the contrary, previous reports indicate there is less $\mathrm{G}_{\mathrm{i}}$ relative to $G_{s}$ in the obese vs. the lean Zucker membranes. The receptor $G_{i}$ protein complex in membranes of obese animals is about fourfold more sensitive to GTP than the complex from lean rats. $\mathrm{G}_{\mathrm{i} \alpha 1}$ and $\mathrm{G}_{\mathrm{i} \alpha 2}$ have both been shown to be low in obese membranes $(24,33)$. However, when those experiments were performed no access to $\mathrm{G}_{\mathrm{i} \alpha}$ recombinant standards was available and the exact specificity of the antibodies was not established. More recent studies in Zucker rats and humans using recombinant standards indicate that it is $G_{i \alpha 1}$ that responds specifically to the obese condition and suggest that $G_{i \alpha 1}$ transduces the adenosine receptor signal $(37,38)$. Likewise, excess $A_{1}$ adenosine receptor number in obese fat cells does not provide the underlying mechanism for the decreased basal lipolytic rate observed in $f a / f a$ rats as comparable receptor density per milligram of protein in adipocytes from lean and $f a / f a$ rats has been reported $(24,32)$.

The present study raises the possibility that the hormonal control of lipolysis is altered in $f a / f a$ rats because the enhanced $A_{1}$ adenosine receptor-mediated inhibition of adenylate cyclase is not counterbalanced by the lipolytic effect of leptin. Under physiological circumstances, leptin could oppose the tonic inhibition of lipolysis of adenosine. Thus, leptin may influence the balance between lipolytic and lipogenic mechanisms, exerting a homeostatic control on fat cells by counteracting the tonic inhibition of lipolysis of endogenous adenosine. But it remains unclear to what extent tonic inhibition by adenosine is actually curtailed by the leptin-induced stimulation of lipolysis under pathophysiological circumstances and whether this effect differs among fat depots.

This is not the first study to report a functional relation between adenosine and leptin. Cheng et al. (39) showed that adenosine appears to be involved in the insulin-stimulated release of leptin from isolated rat adipocytes. Furthermore, the adenosinergic system has been reported to increase leptin secretion by directly activating adenosine $A_{1}$ receptors in fat tissue (40). However, the finding of an $A_{1}$ adenosine receptor- $G_{i}$ signaling effect in leptin-induced lipolysis has not been reported before. Adenosine, acting via the $A_{1}$ receptor coupled to $G_{i}$, accounts for a tonic inhibition of lipolysis in rat adipocytes that cannot be counteracted in the 
leptin receptor-deficient white adipose tissue of $f a / f a$ rats.

The present study does not indicate whether leptininduced lipolysis is accompanied by increases in cAMP or whether, like norepinephrine, leptin activates the hormone-sensitive lipase (17). Addressing these questions may be of physiological relevance since leptin signaling is believed to be transduced via the STAT/ JAK pathway (41) and leptin has been shown to stimulate a novel form of lipolysis in which glycerol is released without a proportional release in free fatty acids (11). The level of expression of G-proteins is sensitive to both the nutritional and hormonal states of the organism (24). Alterations in adenylyl cyclase activity in response to high-energy diets (42) as well as in hypothyroidism (43-45) have been reported. Furthermore, the mechanism of action disentangled here may be applied not only to lipid metabolism regulation, but also to glucose homeostasis and insulin resistance. The molecular basis for the influence of $A_{1}$ adenosine receptors on insulin signaling is not completely known, but several instances of cross-talk between the $G_{i}$ protein pathway and the insulin signal have been reported $(36,46-49)$. It will be interesting to unravel the potential participation of leptin in these phenomena and determine whether the pharmacologic manipulation of this system might be of potential therapeutic interest for the treatment of both obesity and insulin resistance.

In summary, these results strongly suggest that the lipolytic effect of leptin is located at the adenylate cyclase $/ G_{i}$ proteins step. The present study envisages the possibility that leptin may function as an important autocrine physiological regulator signal, controlling lipolysis by opposing the adenosine $\mathrm{A}_{1}$ receptor-mediated inhibition of lipolysis. An altered functional regulation of lipolysis due to defective leptin-induced stimulation could be a molecular mechanism causing or maintaining an increased adipose tissue mass. Thus, regulation of the lipolytic rate of adipocytes appears to depend in part on the balanced effect of the stimulatory response attributable to leptin and the inhibitory response attributable to adenosine. The present study envisages, for the first time, the possibility that leptin is involved in the control of lipolysis by opposing adenosine-mediated tonic inhibition.

\section{REFERENCES}

1. Zhang, Y., Proenca, R., Maffei, M., Barone, M., Leopold, L., and Friedman, J. M. (1994) Positional cloning of the mouse obese gene and its human homologue. Nature (London) 372, 425-432

2. Frühbeck, G., Jebb, S. A., and Prentice, A. M. (1998) Leptin: physiology and pathophysiology. Clin. Physiol. 18, 399-419

3. Chehab, F. F., Lim, M. E., and Lu, R. H. (1996) Correction of the sterility defect in homozygous obese female mice by treatment with the human recombinant leptin. Nat. Genet. 12, $318-320$

4. Cioffi, J. A., Shafer, A. W., Zupancic, T. J., Smith-Gbur, J., Mikhail, A., Platika, D., and Snodgrass, H. R. (1996) Novel B219/OB receptor isoforms: possible role of leptin in hematopoiesis and reproduction. Nature Med. 2, 585-589
5. Sierra-Honigmann, M. R., Nath, A. K., Murakami, C., GarciaCardena, G., Papapetropoulos, A., Sessa, W. C., Magde, L. A., Schechner, J. S., Schwabb, M. B., Polverini, P. J., and FloresRiveros, J. R. (1998) Biological action of leptin as an angiogenic factor. Science 281, 1683-1686

6. Lord, G. M., Matarese, G., Howard, J. K., Baker, R. J., Bloom, S. R., and Lechler, R. I. (1998) Leptin modulates the T-cell immune response and reverses starvation-induced immunosuppression. Nature (London) 394, 897-901

7. Frühbeck, G. (1999) Pivotal role of nitric oxide in the control of blood pressure after leptin administration. Diabetes 48, 903-908

8. Chen, G., Koyama, K., Yuan, X., Lee, Y., Zhou, Y. T., O'Doherty, R., Newgard, C. B., and Unger, R. H. (1996) Disappearance of body fat in normal rats induced by adenovirus-mediated leptin gene therapy. Proc. Natl. Acad. Sci. USA 93, 14795-14799

9. Shimabukuro, M., Koyama, K., Chen, G., Wang, M. Y., Trieu, F., Lee, Y., Newgard, C. B., and Unger, R. H. (1997) Direct antidiabetic effect of leptin through triglyceride depletion of tissues. Proc. Natl. Acad. Sci. USA 94, 4637-4641

10. Wang, Z.-W., Zhou, Y.-T., Lee, Y., Higa, M., Kalra, S. P., and Unger, R. H. (1999) Hyperleptinemia depletes fat from denervated fat tissue. Biochem. Biophys. Res. Commun. 260, 653-657

11. Wang, M.-Y., Lee, Y., and Unger, R. H. (1998) Novel form of lipolysis induced by leptin. J. Biol. Chem. 274, 17541-17544

12. Siegrist-Kaiser, C. A., Pauli, V., Juge-Aubry, C. E., Boss, O., Pernin, A., Chin, W. W., Cusin, I., Rohner-Jeanrenaud, F., Burger, A. G., Zapf, J., Meier, C. A. (1997) Direct effects of leptin on brown and white adipose tissue. J. Clin. Invest. 100, 2858-2864

13. Frühbeck, G., Aguado, M., and Martínez, J. A. (1997) In vitro lipolytic effect of leptin on mouse adipocytes: evidence for a possible autocrine-paracrine role of leptin. Biochem. Biophys. Res. Commun. 240, 590-594

14. Frühbeck, G., Aguado, M., Gómez-Ambrosi, J., and Martínez, J. A. (1998) Lipolytic effect of in vivo leptin administration on adipocytes of lean and $o b / o b$ mice, but not $d b / d b$ mice. Biochem. Biophys. Res. Commun. 250, 99-102

15. Honnor, R. C., Dhillon, G. S., and Londos, C. (1985) cAMPdependent protein kinase and lipolysis in rat adipocytes. I. Cell preparation, manipulation, and predictability in behavior. J. Biol. Chem. 260, 15122-15129

16. Honnor, R. C., Dhillon, G. S., and Londos, C. (1985) cAMPdependent protein kinase and lipolysis in rat adipocytes. II. Definition of steady-state relationship with lipolytic and antilipolytic modulators. J. Biol. Chem. 260, 15130-15138

17. Lafontan, M., and Berlan, M. (1993) Fat cell adrenergic receptors and the control of white and brown fat cell function. J. Lipid Res. 34, 1057-1091

18. Rodbell, M. (1964) Metabolism of isolated fat cells. J. Biol. Chem. 239, 375-380

19. Galitzky, J., Reverte, M., Portillo, M., Carpéné, C., Lafontan, M., and Berlan, M. (1993) Coexistence of $\beta_{1^{-}}, \beta_{2^{-}}$, and $\beta_{3}$-adrenoceptors in $\operatorname{dog}$ fat cells and their differential activation by catecholamines. Am. J. Physiol. 264, E403-E412

20. Wieland, O. (1957) Methode zur Bestimmung von Glycerin. Biochem. Z. 239, 313-317

21. Dole, V. P., and Meinertz, H. (1960) Microdetermination of long-chain fatty acids in plasma and tissues. J. Biol. Chem. 235, 2595-2599

22. Zhao, A. Z., Bornfeldt, K. E., and Beavo, J. A. (1998) Leptin inhibits insulin secretion by activation of phosphodiesterase $3 \mathrm{~B}$. J. Clin. Invest. 102, 869-873

23. Frühbeck, G., and Salvador, J. (2000) Relation between leptin and the regulation of glucose metabolism. Diabetologia 43, 3-12

24. LaNoue, K. F., and Martin, L. F. (1994) Abnormal $A_{1}$ adenosine receptor function in genetic obesity. FASEB J. 8, 72-80

25. Bray, G., and Bouchard, C. (1997) Genetics of human obesity: research directions. FASEB J. 11, 937-945

26. Bottini, E., and Gloria-Bottini, F. (1999) Adenosine deaminase and body mass index in non-insulin-dependent diabetes mellitus. Metabolism 48, 949-951

27. Chagnon, Y. C., Pérusse, L., Weisnagel, S. J., Rankinen, T., and Bouchard, C. (2000) The human obesity gene map: the 1999 update. Obesity Res. 8, 89-117

28. Moxham, C. M., Hod, Y., and Malbon, C. C. (1993) $\mathrm{G}_{\mathrm{i} \alpha 2}$ mediates the inhibitory regulation of adenylcyclase in vivo: 
analysis in transgenic mice with $\mathrm{G}_{\mathrm{i} \alpha 2}$ suppressed by inducible antisense RNA. Dev. Genet. 14, 266-273

29. Bégin-Heick, N. (1985) Absence of the inhibitory effect of guanine nucleotides on adenylate cyclase activity in white adipocyte membranes of the ob/ob mouse. Effect of the ob gene. J. Biol. Chem. 260, 6187-6193

30. Greenberg, A. S., Taylor, S. I., and Londos, C. (1987) Presence of a functional inhibitory GTP-binding regulatory component. $G_{\mathrm{i}}$, linked to adenylate cyclase in adipocytes of ob/ob mice. J. Biol. Chem. 262, 4564-4568

31. Vannucci, S. J., Klim, C. M., Martin, L. F., and LaNoue, K. F. (1989) $\mathrm{A}_{1}$-adenosine receptor-mediated inhibition of adipocyte adenylate cyclase and lipolysis in Zucker rats. Am. J. Physiol. 257, E871-E878

32. Vannucci, S. J., Klim, C. M., LaNoue, K. F., and Martin, L. F. (1990) Regulation of fat cell adenylate cyclase in young Zucker $(\mathrm{fa} / \mathrm{fa})$ rats: alterations in GTP sensitivity of adenosine $A_{1}$ mediated inhibition. Int. J. Obesity 14 (Suppl. 3), 125-134

33. Bégin-Heick, N. (1990) Quantification of the $\alpha$ and $\beta$ subunits transducing elements $\left(\mathrm{G}_{\mathrm{s}}\right.$ and $\left.\mathrm{G}_{\mathrm{i}}\right)$ of the adenylate cyclase activity in adipocyte membranes from lean and obese $(o b / o b)$ mice. Biochem. J. 268, 83-89

34. Martin, L. F., Klim, C. M., Vannucci, S. J., Dixon, L. B., Landis, J. R., and LaNoue, K. F. (1990) Alterations in adipocyte adenylate cyclase activity in morbidly obese and formerly morbidly obese humans. Surgery 108, 228-235

35. Gettys, T. W., Ramkumar, V., Uhing, R. J., Seger, L., and Taylor, I. L. (1991) Alterations in mRNA levels, expression, and function of GTP-binding regulatory proteins in adipocytes from obese mice (C57BL/6J-ob/ob). J. Biol. Chem. 266, 15949-15955

36. Bégin-Heick, N. (1992) $\alpha$-Subunits of $\mathrm{G}_{\mathrm{s}}$ and $\mathrm{G}_{\mathrm{i}}$ proteins in adipocyte plasma membranes of genetically diabetic $(d b / d b)$ mice. Am. J. Physiol. 263, C121-C129

37. Kaartinen, J. M., LaNoue, K. F., and Ohisalo, J. J. (1994) Quantification of the inhibitory G-proteins in fat cells of obese and normal weight human subjects of lean and obese subjects. Biochim. Biophys. Acta 1201, 69-75

38. Berkich, D. A., Luthin, D. R., Woodard, R. L., Vannucci, S. J., Linden, J., and LaNoue, K. F. (1995) Evidence for regulated coupling of $\mathrm{A}_{1}$ adenosine receptors by phosphorylation in Zucker rats. Am. J. Physiol. 268, E693-E704
39. Cheng, J.-T., Liu, I.-M., Chi, T.-C., Shinozuka, K., Lu, F.-H., Wu, T.-J., and Chang, C. J. (2000) Role of adenosine in insulinstimulated release of leptin from isolated white adipocytes of Wistar rats. Diabetes 49, 20-24

40. Rice, A., Fain, J., and Rivkees, S. A. (2000) Al adenosine receptor activation increases adipocyte leptin secretion. Endocrinology 141, 1442-1445

41. Vaisse, C., Halaas, J. L., Horvath, C. M., Darnell, J. E. Jr, Stoffel, M., and Friedman, J. M. (1996) Leptin activation of Stat3 in the hypothalamus of wild-type and ob/ob mice but not $\mathrm{db} / \mathrm{db}$ mice. Nat. Genet. 14, 95-97

42. Kenan, Y., Levinson, M., Pines, M., and Naim, M. (1997) Adenylyl cyclase inhibitory pathway is differentially modified in rat white and brown fat by high-energy diets. Am. J. Physiol. 272, E1043-E1049

43. Malbon, C. C., Rapiejko, P. J., and Mangano, T. J. (1985) Fat cell adenylate cyclase system. Enhanced inhibition by adenosine and GTP in the hypothyroid rat. J. Biol. Chem. 260, 2558-2564

44. Ohisalo, J. J., and Milligan, G. (1989) Guanine-nucleotidebinding proteins $\mathrm{G}_{\mathrm{i}}$ and $\mathrm{G}_{\mathrm{s}}$ in fat-cells from normal, hypothyroid and obese human subjects. Biochem. J. 260, 843-847

45. Milligan, G., and Saggerson, E. D. (1990) Concurrent upregulation of guanine-nucleotide-binding proteins $G_{i 1 \alpha} G_{i 2 \alpha}$ and $\mathrm{G}_{\mathrm{i} 3 \alpha}$ in adipocytes of hypothyroid rats. Biochem. J. 270, 765-769

46. Caro, J. F., Raju, M. S., Caro, M., Lynch, C. J., Poulos, J., Exton, J. H., and Thakkar, J. K. (1994) Guanine nucleotide binding regulatory proteins in liver from obese humans with and without type II diabetes: evidence for altered 'cross-talk' between the insulin receptor and $\mathrm{G}_{\mathrm{i}}$-proteins. J. Cell. Biochem. 54, 309-319

47. Moxham, C. M., and Malbon, C. C. (1996) Insulin action impaired by deficiency of the G-protein subunit $G_{\mathrm{i} \alpha 2}$. Nature (London) 379, 840-844

48. Xu, B., Berkich, D. A., Crist, G. H., and LaNoue, K. F. (1998) $A_{1}$ adenosine receptor antagonism improves glucose tolerance in Zucker rats. Am. J. Physiol. 274, E271-E279

49. Crist, G. H., Xu, B., LaNoue, K. F., and Lang, C. H. (1998) Tissue-specific effects of in vivo adenosine receptor blockade on glucose uptake in Zucker rats. FASEB J. 12, 1301-1308

Received for publication April 27, 2000. Revised for publication July 20, 2000. 